\title{
SOCIEDADE DE RISCO E MEIO AMBIENTE: DANOS PROVOCADOS PELO HIPERCONSUMO E A EFICIÊNCIA DA TRIBUTAÇÃO ECOLOGICAMENTE DIRIGIDA
}

\author{
Joana D’Arc Dias Martins*
}

\begin{abstract}
Resumo
O presente artigo tem como ponto de partida a constatação de que se está diante uma sociedade de risco, e que o consumo irracional tem contribuído de forma significativa para a ampliação desse problema. Logo, uma nova ética na relação do homem com o meio ambiente precisa ser construída, sob pena de grave comprometimento da sobrevivência das espécies. Por outro lado, o Estado dispõe de eficientes mecanismos para conter esse processo, sendo o tributo ecologicamente orientado a principal ferramenta estatal, visto seu forte poder de induzir comportamentos ambientalmente responsáveis. Nesse estudo será utilizado o método dedutivo e a pesquisa bibliográfica.

Palavras-chaves: meio ambiente; sociedade de risco; hiperconsumo; ética; tributação ambiental.

\section{RISK SOCIETY AND THE ENVIRONMENT: THE DAMAGE CAUSED BY HYPER CONSUMPTION AND THE EFFICIENCY OF ECOLOGICALLY DIRECTED TAXATION}

\begin{abstract}
This article has as its starting point the observation that a risk society is facing, and that irrational consumption has contributed significantly to the expansion of this problem. Therefore, a new ethics in the relationship between man and the environment needs to be built, under penalty of serious compromise to the survival of species. On the other hand, the State has efficient mechanisms to contain this process, the ecologically oriented tax being the main state tool, given its strong power to induce environmentally responsible behavior. In this study, the deductive method and bibliographic research will be used.
\end{abstract}

Keywords: environment; risk society; hyperconsumption; ethic; environmental taxation.

\section{Introdução}

O modelo de desenvolvimento adotado a partir da Revolução Industrial, pautado pela busca crescente de produção, atingiu níveis nunca antes imaginados, e como corolário, do consumo, que passou a ser incentivado, pois nada adiantaria produzir muito se não houvesse

\footnotetext{
* Doutoranda e mestre em Direito pela Universidade de Marília - UNIMAR - Marília - São Paulo (Brasil). Especialista em Direito Ambiental pelo Instituto o Direito por um Planeta Verde, Especialista em Direito Público pela Ulbra, campus de Ji-Paraná/RO e em Direito Processual Civil pelo Instituto de Ensino Superior da Amazônia e Centro de Atualização e Estudos Jurídicos de São Paulo. Promotora de Justiça do Estado do Acre. E-mail:
} 
pessoas dispostas a consumir mais e rapidamente aqueles produtos que eram diariamente despejados nos mercados. Por consequência, juntamente com essa revolução, desenvolveu-se progressivamente uma sociedade de consumo dinâmica.

Malgrado, esse modelo equivocado de desenvolvimento, sem nenhuma preocupação com a finitude dos recursos naturais e baseado na equivocada premissa de que todo dano ao meio ambiente seria reversível, construiu uma sociedade que distribui riquezas com a mesma velocidade com que distribui riscos, cujos efeitos são intertemporais, afetando a qualidade de vida dos seres humanos no presente e a sobrevivência das futuras gerações e de todas as espécies que habitam o planeta.

Orientados por essas premissas, urge necessário à formatação de novos paradigmas para a justiça ambiental, a partir da compreensão de que uma nova ética precisa florescer na relação do ser humano com o meio ambiente, balizado pelo Estado e pela coletividade, que devem assumir em definitivo a condução desse processo mediante o concurso de todos os canais de comunicação, inclusive do sistema comunicacional do direito, por meio da construção de normas tributárias indutoras e responsabilidade ambiental.

Entre os instrumentos econômicos colocados à disposição do Estado para a proteção ambiental, o tributo tem se sobressaído, visto acompanhar o fluxo de riquezas do país, pois é justamente do setor privado que o Estado recolhe os recursos de que necessita para cumprimento de suas funções constitucionais, bem como em função do seu forte poder de indução comportamental, demonstrando ser um eficiente mecanismo de proteção ambiental, fomentador da concretização dos mais diversos fins constitucionais.

A possibilidade de adaptar a norma tributária, de modo a torná-la mais ou menos gravosa diante de determinada situação, decorre do fim extrafiscal do tributo. Essa possibilidade estará presente sempre que o escopo primordial da norma tributária não for a arrecadação de recursos para os cofres públicos, mas, sobretudo, a concretização de desígnios constitucionais.

Assim, a tributação deixou de ser um mero instrumento fiscal para ocupar um importante papel de concretizador de políticas públicas e sociais. E a tributação ambiental está justamente inserida nesse contexto, possuindo um nítido caráter extrafiscal.

A pesquisa se justifica principalmente pela atualidade e a relevância do tema. $\mathrm{O}$ método de abordagem é dedutivo e a técnica de pesquisa será bibliográfica e documental. O artigo está dividido em três tópicos que seguem os objetivos específicos do trabalho. 


\section{1. Ética e responsabilidade ambiental}

A expressão sociedade de risco surge no âmbito da sociologia ao serem analisadas as características que marcam a sociedade da segunda modernidade. Essa sociedade, concebida no intuito de ampliar o conforto e a qualidade de vida dos seres humanos, paradoxalmente está marcada pela insegurança constante e pela produção de riscos globais que comprometem a própria existência no planeta. Segundo o sociólogo alemão Ulrick Beck (2002, p. 29), os desafios da sociedade de risco são os perigos produzidos pela civilização e que não podem ser delimitados socialmente, nem no tempo nem no espaço.

No entender de Ulrick Beck (2002, p. 2), esse rápido progresso ocasionou a substituição da primeira modernidade - simples, lineal e industrial, baseada nas sociedades de Estado-Nações - na qual as relações, as redes sociais e as comunidades eram entendidas num sentido territorial.

O Prêmio Nobel de química, Paul Crutzen, apelidou essa segunda modernidade como era do "Antropoceno" (SACHS, 2008, p. 67). Trata-se de uma época em que a Terra está dominada pelo ser humano - o "homo faber". Segundo Sachs (2008, p. 55), esse tempo é único em relação à tecnologia, aumento populacional e crescimento econômico. Tem-se, portanto, um mundo dinâmico e interconectado, mas, paradoxalmente, o Planeta está sendo empurrado para o colapso. A Terra está em seu limite e pela primeira vez na história uma única espécie tem o futuro do planeta em suas mãos. Os seres humanos detonaram uma nova era geológica: o Antropoceno.

Portanto, a racionalidade do modelo de desenvolvimento atual, que busca o crescimento econômico sem limite, está comprometendo a dinâmica de todos os sistemas fundamentais para preservação da vida e transformando o Planeta sem respeitar os limites físicos da biosfera. O resultado desse estilo equivocado de vida é, nas palavras de Sachs (2008, p. 44), um planeta abarrotado, um modelo que privilegia o capital artificial em detrimento do natural, e que pensa que a natureza é descartável.

E esse novo modelo de vida, conforme analisado por Anthony Giddens (1991, p. 14), desvencilhou-se na quase totalidade de todos os tipos tradicionais típicos da ordem social precedente, e como corolário, as mudanças ocorridas durante os últimos séculos foram tão dramáticas e abrangentes em seus impactos, que a sociedade atual sequer detém suficiente 
conhecimento e capacidade para interpretar e medir os riscos de tais alterações.

$\mathrm{Na}$ maior parte das culturas pré-modernas, mesmo nas grandes civilizações, os seres humanos se viam em perfeita sintonia com o meio ambiente, e suas vidas se encontravam entrelaçadas aos movimentos e às disposições da natureza, baseados na disponibilidade das fontes naturais do sustento, na prosperidade das plantações e animais, além dos próprios desastres naturais que eventualmente poderiam ocorrer (GIDDENS, 1991, p. 66).

Nesse período, o único ambiente de risco era aquele ligado às vicissitudes de um mundo físico, normalmente relacionado às altas taxas de mortalidade infantil, baixa expectativa de vida, vulnerabilidade dos indivíduos a moléstias e pragas, receio dos efeitos devastadores de eventos naturais - inundações, tormentas, etc. -, atuação de exércitos invasores, saqueadores e piratas, que circundavam as aldeias. Afora tais riscos, de caráter eminentemente local e regionalizado, havia o risco oriundo da forte influência da própria Igreja, considerado um dos mais temíveis da Antiguidade, o medo de cair em desgraça pelo pecado (GIDDENS, 1991, p. 108-110).

Portanto, conquanto a ausência de cuidados ambientais na era pré-moderna também se mostrasse recorrente, suas consequências eram detectadas sensorialmente, além de que, hodiernamente se encontrava relacionada à falta de higiene. Diferentemente, na civilização atual os riscos produzidos, na maioria das vezes, sequer são perceptíveis, porque estão camuflados, afetando os sistemas vitais sorrateiramente. Além disso, não decorrem de uma subprovisão de tecnologia higiênica, ao contrário, suas causas estão ligadas à superprodução industrial, como assegura Ulrick Beck (2019, p. 26):

Os riscos e ameaças atuais diferenciam-se, portanto, de seus equivalentes medievais, [...] fundamentalmente por conta da globalidade de seu alcance (ser humano, fauna, flora) e de suas causas modernas. São riscos da modernização. São um produto de série do maquinário industrial do progresso, sendo sistematicamente agravados com seu desenvolvimento ulterior.

À vista disso, a sociedade atual, outrora acostumada com a previsibilidade das situações, convive agora com a insegurança constante de novas e inesperadas ameaças, cujas soluções são cobradas insistentemente de um Estado que não dá conta de saná-las.

Nesse novo rearranjo social, começam a tomar corpo as ameaças produzidas até então pelo modelo econômico da sociedade industrial, baseado em um progressivo 
desequilíbrio proporcionado pelo crescimento e aperfeiçoamento das necessidades humanas, conjugados a um sistema que não se atentou ao necessário respeito à esgotabilidade dos recursos naturais, dando ensejo a uma verdadeira crise ambiental na qual a sociedade passa a conviver com risco permanente de desastres e catástrofes sobre os quais não tem mais controle.

Diante desse cenário, nem mesmo o desenvolvimento científico acumulado ao logo dos anos tem sido capaz de aferir o teor dos riscos gerados pela incessante produção de riqueza. O perigo passou a ser uma realidade muito vívida e pode estar em todo lugar. $\mathrm{E}$ isso tudo acontece sem que se possa avaliar adequadamente a potencialidade dessa ameaça. Nesse sentido os escólios de Simone Sebastião (2011, p. 178):

\begin{abstract}
Os riscos socioecológicos da contemporaneidade são peculiares, na medida em que, sendo provenientes do próprio desenvolvimento tecnológico e econômico, e originários das engenharias nuclear, química, ambiental e genética, são de difícil identificação no tempo e no espaço, atingindo escala global. Além disso, são, muitas vezes, invisíveis, superando os sistemas de segurança. Exemplo típico é o caso da explosão do reator na usina nuclear de Chernobyl, na Ucrânia, na qual, inclusive, as previsões científicas falharam.
\end{abstract}

Por conseguinte, os riscos gerados pela sociedade pós-industrial alcançam nações e classes sociais sem respeitar fronteiras, numa tendência globalizante que converte o processo da modernização em tema e problema, originando uma crescente reflexividade, tendo em vista que "A promessa de segurança avança com os riscos e precisa ser, diante de uma esfera pública alerta e crítica, continuamente reforçada por meio de intervenções cosméticas ou efetivas no desenvolvimento técnico-econômico" (BECK, 2019, p. 24).

Nota-se, portanto, que na atualidade, o dano ambiental tem condições de projetar seus efeitos no tempo sem haver uma certeza e um controle de seu grau de periculosidade. É possível citar como exemplos os danos anônimos (impossibilidade de conhecimento atual), cumulativos e invisíveis, o efeito estufa, chuva ácida e muitos outros. Os referidos exemplos são provas incontestáveis da crise ambiental, bem como da necessidade de implantar formas alternativas de reparação do dano e de compensação ecológica.

Dentro desse novo marco da realidade, adverte Peralta Montero (2014, p. 48) que os riscos são multicausais, imperceptíveis e de consequências imprevisíveis e imensuráveis. Tem caráter global e sinérgico, não respeitam fronteiras nem as diferenças sociais. Seus efeitos são intertemporais, afetando a qualidade de vida dos seres humanos no presente e a sobrevivência 
das futuras gerações e todas as espécies que habitam o planeta.

Ademais, toda essa proliferação das situações de risco acaba por vitimizar não só a geração presente, projetando-se, também, para as futuras gerações. No que concerne ao elemento tempo, Ayala (2003, p. 32) destaca que o sistema jurídico protetivo deve ser apreciado como um elemento fundamental “[...] nas opções e seleção das medidas de controle dos riscos, porque a qualidade global e o anonimato potencial expõem o desenvolvimento da vida a estados de insegurança, cujo momento e duração não podem ser cientificamente determinados com a certeza suficiente".

Consequentemente, os riscos possuem agora grande aptidão de expor uma série indeterminada de sujeitos a estados de desfavorabilidade, estendendo-se potencialmente em uma escala global e afetando, também, os membros das futuras gerações, com resultados de decisões atribuíveis à limitada participação de membros dessa geração, responsáveis pela proliferação de riscos globais, intergeracionais (GIDDENS, 1991, p. 126-127).

Diante de tal contexto, a capacidade para conciliar desenvolvimento econômico em longo prazo e equilíbrio ambiental está sendo objeto de um debate profundo em diversos âmbitos do conhecimento. Segundo Peralta Montero (2014, p. 43) " [...] a atual trajetória da atividade humana é insustentável em longo prazo; os próprios limites do meio ambiente acabarão frustrando as nossas aspirações globais de propriedade. Repensar essa forma de vida é sem dúvida um dos maiores desafios da sociedade atual".

A verdade é que o homem, na busca incessante pelo crescimento econômico, esqueceu-se de integrar o elemento ecológico como parte do desenvolvimento. Logo, percebe-se que a problemática ambiental moderna é o resultado de uma crise da civilização. Nesse tocante, Enrique Leff (2006, p. 15) explica que:

Não é uma catástrofe ecológica nem um simples desequilíbrio da economia. É a própria desarticulação do mundo ao qual conduz a coisificação do ser e a superexploração da natureza; é a perda do sentimento da existência que gera pensamento racional em sua negação da autoridade.

De mais a mais, embora os riscos produzidos pela modernidade afetem de forma mais contudente as classes sociais menos assistidas, como as mazelas de um modo geral, um novo componente surge nessa lógica distributiva, denominada de "efeito bumerangue", o que acaba por desconfigurar o esquema de classes, deixando todos em situação de vulnerabilidade, independentemente de suas posições econômicas. Ulrick Beck (2019, p. 27) 
aponta que "os riscos da modernização cedo ou tarde acabam alcançando aqueles que os produziram ou lucraram com eles". Revela-se, nesse ponto, o caráter supranacional dos riscos que emanam dos meios de produção da modernidade tardia. Os limites fronteiriços são sistematicamente rompidos, não só em sua pura acepção geográfica, mas sobremodo em seu aspecto geopolítico, com ameaças à legitimidade, à propriedade e ao lucro.

Consequentemente, nessa nova sociedade de risco, os processos de disputa já não se dão mais em relação ao acesso e à distribuição de bens, mas no poder de evitar ou distribuir os males provindos da própria modernização. Logo, criou-se uma igualdade negativa em que os riscos ecológicos de grande consequência passam a ser democráticos e as pessoas tornamse iguais, não mais pelos seus direitos ou benefícios que alcançam, mas pelos males ambientais que compartilham (LENZI, 2006, p. 133-134).

Assim sendo, após anos de pressão sobre os bens ecológicos e de aplicação de um modelo econômico totalmente equivocado, baseado na crença cega advinda do benefício dos ganhos tecnológicos e científicos, depara-se com uma sociedade que fecundou em seu próprio berço perigos e riscos incalculáveis para a sua sobrevivência. Uma sociedade "que distribui riqueza" com a mesma velocidade com que "distribui riscos" (BECK, 2019, p. 25).

É bem verdade que qualquer ação humana pode gerar riscos, porém, é preciso divisar riscos pessoais, normalmente apresentados com tonalidade de ousadia e aventura, daquelas situações de ameaça global, que podem afetar toda a humanidade com possível destruição das mais variadas formas de vida na Terra.

Outrossim, a natureza já não pode mais ser pensada sem a sociedade, e a sociedade já não pode ser pensada sem a natureza. As antigas teorias sociais dos séculos passados que pensavam a natureza como algo dado, destinado a se submeter, não podem mais ser aplicadas (BECK, 2019, p. 89).

Acerca da ação humana sobre a natureza, Pereira et al (2015, p. 148) menciona que "o meio ambiente foi atingido pela modernidade de uma forma nunca vista anteriormente. Nessa seara, a modernidade elevou o aquecimento global com o uso do gás carbônico produzido por suas máquinas e jogado na atmosfera; poluiu rios e mares; [...]”. E segue afirmando que:

Os riscos advindos da sociedade moderna, em grande parte, surgem pelo direcionamento das decisões em busca dos progressos tecnológico e econômico, despreocupado com a qualidade ambiental e, na mesma esteira, 
preocupado exclusivamente com o lucro. (PEREIRA et al., 2015, p. 152).

Portanto, a preocupação com os danos ao meio ambiente está agora difundida e é foco de atenção para os governos em todo o mundo. Ademais, com a explosão social do risco, a irresponsabilidade organizada, segundo ponderações lançadas por Ulrick Beck (2019, p. 234), é colocada em xeque, e as estratégias para ocultar as contradições institucionais tornamse meta do "escrutínio público".

Aqui reside um ponto fundamental, pois uma nova forma reflexiva, de ver e entender o mundo, precisa ser imposta. A formação desta "nova sociedade" exige uma inovadora modalidade de interpretar o mundo, em que todos os seres vivos são membros de comunidades ecológicas ligadas umas às outras, em uma rede de interdependência (SCHONARDIE, 2004, p. 54).

Consequentemente, a tomada de decisões pelo ser humano, no tocante à proteção do meio ambiente frente à sociedade de risco, deve ser necessariamente pautada pela moralidade, uma vez que as consequências da intervenção na natureza podem abarcar, não espantosamente, a sobrevivência da própria espécie humana (FENSTERSEIFER, 2008, p. 58$59)$.

De resto, não há que se olvidar que no contexto de globalização dos riscos, "poucas pessoas, em qualquer lugar do mundo, podem continuar sem consciência do fato de que suas atividades locais são influenciadas, e às vezes até determinadas, por acontecimentos ou organismos distantes", de forma que uma decisão de consumir determinados produtos pode gerar severas implicações, que vão desde a sobrevivência de alguém do outro lado do mundo até a deflagração de um processo de deterioração ecológica com consequências para toda a humanidade (GIDDENS, 2012, p. 91-92).

Enfim, diante da manifesta ameaça ecológica a que a atual sociedade se encontra submetida, mostra-se indispensável inserir a ética no debate da problemática ambiental. Desse modo, o discurso ético deve caminhar conjuntamente com o discurso ambiental visando permitir ao homem reorientar seu relacionamento com a natureza, de modo que o desenvolvimento seja duradouro e sustentável.

\section{Danos ambientais provocados pelo hiperconsumo}


No contexto da sociedade de risco, outro aspecto de relevo a ser apurado neste estudo envolve o papel do consumo na degradação dos bens ambientais e quais os caminhos a serem perseguidos visando à reversão desse processo.

O ato de consumir, por si só, não é um problema, sendo algo natural e essencial para a manutenção da vida no planeta. Sua origem, segundo preceitua Zygmunt Bauman (2008, p.37), remonta à origem dos seres vivos:

Se reduzido à forma arquetípica do ciclo metabólico de ingestão, digestão e excreção, o consumo é uma condição, e um aspecto permanente e irremovível, sem limites temporais ou históricos; um elemento inseparável da sobrevivência biológica que nós humanos compartilhamos com todos os outros organismos vivos. Visto dessa maneira, o fenômeno do consumo tem raízes tão antigas quanto os seres vivos - e com toda certeza é parte permanente integral de todas as formas de vida conhecidas a partir de narrativas históricas e relatos etnográficos.

Porém, quando esse consumo passa a ser praticado de forma imoderada, levando à exploração excessiva dos recursos naturais e interferindo no equilíbrio do planeta, surgem graves problemas relacionados aos impactos ambientais decorrentes dessa conduta.

É seguro asseverar que as mudanças no ambiente ecológico do planeta são influenciadas, de forma direta, em razão do aumento da população mundial e pelo modo irresponsável e sem maiores preocupações com que a humanidade vem transformando, consumindo e descartando os resíduos sólidos. Assim, o comportamento humano, especialmente ligado ao excesso de consumo e à produção industrial, tem relação direta com o comprometimento do equilíbrio ecológico do planeta, o que denota a intrínseca ligação entre a questão da proteção ambiental e ao desenvolvimento econômico dos Estados.

O consumo desregrado é aquele realizado de forma irresponsável, impulsionado pela "plena felicidade" propagada pelos canais de comunicação, que utilizam de diversos artifícios, como a imagem de celebridades do cinema, da música e da televisão, com vistas a produzir encantamento e efetivar a sedução por consumir cada vez mais (VIEIRA; REIS, 2016, p. 142).

Por outro lado, o aumento do consumo experimentado nas últimas décadas, a princípio, poderia ser atribuído à multiplicação crescente da população no planeta, sobremodo a partir do século XVIII, porém, mesmo sem se olvidar do impacto relevante que o fenômeno representa, decerto que essa não é sua causa preponderante. Até porque não há uma 
uniformidade entre o consumo e a população, ao contrário, o que salta aos olhos é o império da desigualdade social e o consumo excessivo realizado por uma pequena parcela da população. Segundo uma pesquisa divulgada em 2017 pelo Instituto Brasileiro de Geografia e Estatística (IBGE), os ricos no Brasil gastam 10 vezes mais que a população pobre (BRANDÃO JUNIOR; CHIARINI, 2019).

Perfilhando esse mesmo entendimento, as lições de Fensterseifer e Sarlet (2017, p. 71):

O mesmo raciocínio, trazido para o âmbito interno dos Estados nacionais, permite concluir que tal quadro de desigualdade e injustiça - de cunho social e ambiental - também se registra entre pessoas pobres e ricas que integram determinada comunidade estatal. No caso do Brasil, que registra um dos maiores índices de concentração de renda do mundo, de modo a reproduzir um quadro de profunda desigualdade e miséria social, o fato de algumaas pessoas disporem de alto padrão de consumo - e, portanto, serem gandes poluidoras, -, ao passo que outras tantas muito pouco ou nada consomem, também deve ser considerado para aferir sobre quem deve recair o ônus social e ambiental dos danos ocasionados pelas mudanças climáticas e pela degradação ambiental em geral.

É notório que a demanda atual por recursos naturais se tornou insustentável e exerce grande pressão sobre a biodiversidade do planeta, implicando consequências nefastas para o equilíbrio da Terra. Segundo o relatório "Planeta Vivo" divulgado pela organização ambientalista Fundo Mundial para a Natureza (WWF-2012), a população mundial já estaria consumindo $50 \%$ a mais de recursos que o planeta poderia produzir de forma sustentável, e se não houver uma mudança de comportamento, em 2030, mesmo dois planetas não seriam suficientes para suportar tamanha demanda. Já no relatório, o "Estado do Mundo", The WorldWatch Institute (WWI-2010) aponta que hoje são extraídos anualmente 60 bilhões de toneladas de recursos naturais. Isto representa 50\% a mais do que era extraído há 30 anos. Vêse, pois, que se caminha a passos largos para a implementação da já insuportável degradação ambiental.

Infelizmente, o que se vê é que o estilo de desenvolvimento vigente privilegia a cultura do desperdício, do descartável. Assim, num círculo vicioso de consumismo, o ser humano acaba sendo fetiche de uma cultura do efêmero, que negligencia o valor imaterial da natureza.

Todavia, esse consumismo irresponsável cobra um alto preço, ocasionando danos 
irreparáveis à natureza, que a cada dia se torna mais fragilizada, resultante dos rejeitos e da utilização de matéria-prima e materiais poluentes utilizados na produção. Nesse campo, o planeta começa a dar sinal e insuficiência de condições tanto no que se refere ao fornecimento de matéria-prima quanto à absorção de rejeitos" (PEREIRA et al., 2009, p. 15-16).

Logo, percebe-se que o comportamento individualista, em que o social passa ao largo da felicidade buscada, é um dos maiores obstáculos para se chegar à conscientização do consumidor quanto à sua responsabilidade no atual estágio de degradação ambiental em que o planeta se encontra. O indivíduo pensa em si e para si num verdadeiro "darwinismo social" (PEREIRA et al, 2009, p.16), em que o poder é uma qualidade inerente ao grande consumidor.

Assim, envolvido pelo desejo consumista que beira a insanidade, o homem relaciona-se com a natureza como se as matérias-primas fossem inesgotáveis, e que ela estivesse ali simplesmente para lhe servir, pois ao se ver em situação de predominância, se qualifica como seu "dono e senhor" (CARVALHO, 2003, p. 16). O ser humano deixou de somente usufruir dos bens naturais visando sua sobrevivência para agora explorar a natureza em níveis insuportáveis.

Porém, essa visão do meio ambiente não é sustentável e destoa da realidade da crise ecológica vivenciada. E os danos ambientais, fortemente fomentados por esta característica consumista, têm reflexos diretos na qualidade de vida da sociedade.

Destarte, não remanescem dúvidas de que a crise ambiental se interralaciona aos atuais padrões humanos de consumo ligado ao poder, produção e capital, além de um forte ensejo desordenado por crescimento tecnológico, científico e econômico, sem qualquer previsibilidade de seus efeitos futuros. O progresso e a promessa moderna de felicidade terrena massificaram a produção e o consumo. Nesse cenário, o meio ambiente passou a ser depredado e o planeta acabou por adentrar em um tempo de caos, de variações pluviométricas, climáticas, dentro outros.

O planeta Terra é a casa de todos os seres vivos e, como tal, precisa ser tratado. Não se pode mais conceber que a sociedade admita evoluir à custa dos recursos naturais, mormente após os evidentes impactos negativos que tem provocado na natureza. Conforme é consabido, há uma íntima ligação entre o ser humano e o meio ambiente, e sem sua manutenção, a própria vida na terra encontra-se seriamente ameaçada. Os elementos úteis ao homem contidos na natureza devem ser usados dentro dos seus limites, respeitando-se a 
capacidade suporte de um ecossistema equilibrado. "É importante que se analise a natureza não apenas como um bem econômico, ou um bem de consumo, mas como um ente necessário à sobrevivência do homem e do planeta" (PEREIRA et al, 2008, p. 25).

No mesmo sentido, Hans Jonas (2006, p. 230), ao tratar da forma egoísta com que o homem se relaciona com a natureza, e a sua importância para manutenção da vida humana, pontua:

Esse foi o ponto de vista prático de todos os tempos, ao longo dos quais o conjunto da natureza parecia invulnerável, estando, portanto, inteiramente disponível para os homens, como objeto de usos particulares. Mas se o dever em relação ao homem se apresenta como prioritário, ele deve incluir o dever em relação à natureza, como condição de sua própria continuidade e como um dos elementos da sua própria integridade existencial.

Ainda, tratando da incessante evolução da sociedade à custa dos recursos naturais, o mesmo autor (JONAS, 2006, p. 301) dispõe que "em última instância, não se trata de saber precisamente o que o homem ainda é capaz de fazer - nesse aspecto se pode ser prometéico e sangüíneo - mas o quanto a natureza é capaz de suportar. Ninguém duvida que haja tais limites" (sic).

Portanto, a atual crise ambiental remonta à errônea concepção propagada durante anos a respeito da infinitude dos recursos naturais e de que todo dano ao meio ambiente seria reversível. A falsa premissa de que o homem seria o senhor supremo da natureza e portador de exclusivos direitos sobre esta, podendo dela se utilizar conforme seu bel-prazer, a conferir um tratamento de apenas mais uma mercadoria.

Diante desse contexto, forçoso concluir que o desenvolvimento econômico somente poderá ser aceito e buscado quando coexistir em harmonia com sustentabilidade socioambiental. Não se pode mais admitir o uso irracional e excessivo dos bens naturais que estão disponíveis, até porque, segundo os ensinamentos de François Ost (1995, p. 34) “[...], o homem tem mandato de gestão dos recursos naturais, os seus poderes não são, contudo, os poderes ilimitados do proprietário soberano, mas antes os do administrador prudente que deverá apresentar contas ao senhor".

Faz-se necessário, conforme preceitua a teoria da sociedade de risco, buscar a formatação de uma nova e diferente dialética entre o homem e a natureza, na qual se trabalhe de forma simultânea a tentativa de restauração do equilíbrio ecológico, do sistema econômico, 
das bases produtivas e da dignidade de vida da pessoa humana. Essencial que ocorra a adequada e prudente análise reflexiva dos reais interesses humanos, de grupos presentes e futuros, bem como das condições necessárias para a própria sobrevivência da vida no planeta.

Por conseguinte, e dada a sua imprescindibilidade para a manutenção da vida na Terra, a proteção ambiental necessita de planejamento e participação popular, aliado à conscientização de que os recursos naturais são finitos e que seu uso responsável é fundamental para não comprometer a vida, presente e futura.

\section{Meio ambiente e consumo}

Diante dos problemas ambientais da atualidade, vive-se no planeta Terra sob a égide de um problema de grande magnitude: como conciliar o consumo e o crescimento populacional com a preservação de um ambiente equilibrado, de modo a garantir o acesso aos recursos naturais às gerações futuras?

O que se sabe é que os atuais hábitos de consumo e, além deles, a demanda cada vez mais crescente do mercado por produção cobra um alto preço, ocasionando danos irreparáveis à natureza, que a cada dia se torna mais vulnerável, resultante dos rejeitos e da utilização de matéria-prima e materiais poluentes utilizados na produção.

A crise ambiental trouxe novos desafios para as sociedades modernas, exigindo uma alteração no rumo civilizatório. E na tentativa de escapar da catástrofe ambiental, os sistemas sociais estão se adaptando a essa nova realidade (GADOTTI, 2009, p. 43). Nesse ambiente de mudanças e adaptações, as relações de consumo não poderiam ficar alheias, por fazerem parte do cotidiano social. À vista disso, a educação ambiental pode se configurar no viés de aproximação entre consumidores e o consumo sustentável.

Diante desse contexto, e da premente necessidade de se adotar condutas que revertam em benefícios ao meio ambiente, resta evidenciado que a interação entre o Direito e a Economia permitirá a utilização dos tributos como elemento de controle do consumismo, visando induzir comportamentos ecologicamente corretos por parte de todos envolvidos nas cadeias de produção e de consumo.

Vários fatores podem influenciar a demanda e oferta do mercado. Porém, um fato incontroverso acerca desse movimento do mercado é que a tributação ambiental, quando bem empregada, conjugada com investimentos em educação ambiental, tem o poder de 
desestimular o consumo de determinados produtos, tidos como mais degradantes ou que importe em um maior malefício à saúde, influenciando decisivamente na escolha do consumidor e, consequentemente, contribuindo de forma eficaz para a melhoria da qualidade ambiental.

\subsection{O tributo ecológicamente orientado como mecanismo de controle do consumo para}

\section{fins de preservação ambiental}

O livre jogo do mercado, defendido por Adam Smith no auge do liberalismo, mostrou-se insuficiente para tratar do interesse da proteção ambiental, possibilitando a ocorrência de falhas de mercado e exigindo a intervenção do Estado na economia com forma de resguardar os interesses coletivos a um meio ambiente ecologicamente equilibrado.

Por conseguinte, incumbe ao Estado intervir na economia visando assegurar o bemestar coletivo. Conforme as lições de Washington Peluso (1999, p. 330), ao regulamentar a economia, o Estado atua por medidas legais executivas de fiscalização da prática econômica privada nos mercados, de incentivo a essa atividade, suplementando-a e planejando-a pela introdução de medidas que vão além do funcionamento autorregulado do mercado pelas suas próprias forças.

Logo, aquelas atividades econômicas que provocam degradação ambiental, e que invés de internalizar suas externalidades, atribui esses custos marginais à sociedade, que não participou dessa atividade, conclamam que o Estado intervenha, seja obrigando o agente econômico a reduzir os efeitos das externalidades, seja com o objetivo de introduzir seus custos no sistema de preços, o que pode ser feito através de comando e controle ou de instrumentos econômicos.

Amaral (2007, p. 44), ao tratar das externalidades que ocasionam falhas de mercado, aponta os tributos ambientais como eficiente instrumento a ser utilizado para correção dessas falhas, visto sua capacidade de implementar mudanças comportamentais e introduzir no mercado econômico práticas mais éticas e amigas do ambiente:

[...] dentre vários instrumentos para concretização dessas políticas estatais, pode-se revelar eficiente a utilização de tributos, com o intuito de obrigar os agentes econômicos a suportar as externalidades negativas geradas e razão da sua atividade econômica poluidora ou, por outro lado, estimular por meio 
de incentivos fiscais que eles desenvolvam comportamentos não agressores ao meio ambiente. (AMARAL, 2007, p. 44)

Portanto, não há que se olvidar que dentro desse contexto de integração das políticas ambientais às demais políticas públicas, a política tributária se sobrepõe e está intimamente ligada a todas as outras, eis que originam de sua implantação e execução os recursos que irão financiar os programas e projetos vinculados a cada uma daquelas políticas.

O Estado, através da edição de normas jurídicas, detém o atributo da coerção, e como consequência, através da tributação ambiental, pode estimular comportamentos que tenham como finalidade objetivos previstos constitucionalmente, entre eles a preservação do meio ambiente.

A função fiscal do Estado, calcada no objetivo de arrecadar recursos financeiros para prover os cofres públicos e garantir o bem comum é bem conhecida e aceita. Porém, sobremodo quando se trata de questões ambientais, o caráter extrafiscal dos tributos se sobressai, pois é um importante instrumento estatal de intervenção na economia. Logo, deixa o direito tributário de ser mero instrumento arrecadador para se tornar um dos meios de transformação da sociedade.

Fernanda Vasconcellos (2006, p. 236), ao tratar da função extrafiscal do tributo na seara ambiental, leciona que a imposição de imposto ecológico tem por finalidade compensar, por meio de uma indenização, eventuais danos causados ao meio ambiente, objetivando sua recomposição e ainda a inibição de condutas lesivas, através de uma coerção pecuniária que sirva de desestimulo para a prática de ilícitos ambientais.

Vê-se, pois, que a tributação ambiental, principalmente voltada para sua faceta extrafiscal, é um importante mecanismo para a proteção ambiental, pois através da oneração e, principalmente da desoneração fiscal, mediante a concessão de isenções ou incentivos fiscais, o ente tributante consegue estimular determinadas condutas a serem adotadas pelos contribuintes.

Do ponto de vista econômico, a tributação ambiental negativa, que concede benefícios e isenções fiscais, se mostra mais eficiente, pois induz o setor produtivo à uma nova perspectiva de lucros, estimulando a utilizar tecnologias limpas e corrigindo a poluição na fonte, tendo em vista que os investimentos em tecnologia para produção ecologicamente correta será compensado pela redução na carga tributária e pelo crescimento da demanda, visto que a medida que evita a poluição, a empresa ainda atrai o consumidor que estará 
estimulado a adquirir esses produtos, principalmente, por sua adequação ao meio ambiente. (WILDNER; OTOBELLI, 2011, p. 189)

Existem várias espécies de incentivos fiscais que podem ser utilizados com sucesso na defesa do meio ambiente, entre eles podem-se citar as imunidades, isenções, alíquotas reduzidas, suspensão de impostos, créditos especiais, dentre tantos outros. Independentemente do mecanismo adotado, todos eles têm a finalidade de impulsionar ou atrair os particulares para a prática de atividades elegidas pelo Estado como prioritárias.

Por meio desses incentivos é possível cogitar-se do alcance de uma coexistência harmônica entre economia e meio ambiente. Como bem reflete Derani (2001, p. 132), o tão aclamado desenvolvimento sustentável implica no ideal de um desenvolvimento harmônico da economia e da ecologia, que devem ser ajustadas numa correlação de valores, onde o máximo econômico reflita igualmente um máximo ecológico.

Resta, pois, incontroverso, que os tributos ambientais são um importante instrumento de materialização de políticas públicas de natureza social, econômica e política, por fomentar ou desestimular certas ações, condutas ou atividades, funcionando como meio de indução às ações favoráveis aos fins perseguidos pelo Estado.

\section{Considerações finais}

Conforme restou demonstrado no presente artigo, as intervenções praticadas pelo homem no meio ambiente vem ampliando progressivamente as possibilidades de riscos ambientais, podendo comprometer gravemente todas as formadas de vida na terra.

Nesse contexto, a sociedade contemporânea caminha rumo a uma civilização fundamentada no risco, na qual ônus e benesses são socializados numa mesma trama mundial que a todos envolve. Na marcha em direção a um novo modelo de convivência, a humanidade segue ameaçando a si mesma, tendo em vista que a sociedade distribui a um só tempo riquezas e riscos.

À vista disso, restou demonstrado que os tributos que levam em consideração valores ambientais são eficientes instrumentos de proteção ambiental, visto sua capacidade de implementar mudanças de comportamentos dos contribuintes.

Por conseguinte, em se tratando de questões ambientais, o caráter extrafiscal dos tributos deve ser considerado, vez que é um importante instrumento utilizado pelo Estado para 
intervir na economia e instrumento de materialização de políticas públicas de natureza ambiental que podem ser aliadas com ações econômicas, sociais, entre outras, com o objetivo de estimular ou desestimular certas ações, condutas ou atividades, que propiciem ações favoráveis às finalidades que devem ser direcionadas pelo Estado.

Por fim, além das ações do Estado em prol do meio ambiente saudável é preciso que toda sociedade tenha consciência do seu papel no cenário da sustentabilidade com as adequações e readequações do consumo de bens que possam contribuir neste processo, incluindo aí a educação ambiental.

\section{Referências bibliográficas}

AMARAL, Paulo Henrique do. Direito Tributário Ambiental. São Paulo: Revista dos Tribunais, 2007.

AYALA, Patryck de Araújo. A proteção jurídica das futuras gerações na sociedade do risco global: direito ao futuro na ordem constitucional brasileira. In: LEITE, José Rubens Morato; FERREIRA, Heline Sivini (orgs). Estado de direto ambiental: perspectivas. Rio de Janeiro. Forense Universitária, 2003.

BAUMAN, Zygmunt. A vida para o consumo: A transformação das pessoas em mercadoria. Rio de Janeiro: Jorge Zahar, 2008.

BECK, Ulrich. La sociedade del risgo global. Madrid: Siglo Veintiuno, 2002.

BECK, Ulrich. Sociedade de risco: Rumo a uma outra modernidade. Trad.

Sebastião Nascimento. São Paulo: Editora 34, 2019.

BRANDÃO JUNIOR, Nilson; CHIARINI, Adriana. Ricos gastam 10 vezes mais que os pobres no Brasil. Jornal O Estadão de São Paulo. Disponível em:

https://economia.estadao.com.br/noticias/geral,rico-gasta-10-vezes-mais-que-pobrenobrasil,43444. Acesso: 16 mai. 2021.

CARVALHO, Carlos Gomes de. O que é o Direito Ambiental: dos descaminhos da casa à harmonia da nave. Florianópolis: Habitus, 2003.

CAVALCANTE, Denise Lucena: Tributação ambiental: Por uma remodelação ecológica dos tributos. Nomos: Revista de Pós-Graduação em Direito da UFC. Fortaleza, v. 32, 2002. p. 101-115. Disponível em: http://www.repositorio.ufc.br/handle/riufc/12126. Acesso: 19 de jun. 2021.

DERANI, Cristiane. Direito ambiental econômico. São Paulo: Max Limonad, 2001.

FENSTERSEIFER, Tiago. Direitos fundamentais e proteção do ambiente: a dimensão ecológica da dignidade humana no marco jurídico-constitucional do Estado Socioambiental 
de Direito. Porto Alegre: Livraria do Advogado, 2008.

FENSTERSEIFER, Tiago; SARLET, Ingo Wolfgang. Direito constitucional ambiental. 5. ed. rev., atual. e ampl. São Paulo: Revista dos Tribunais, 2017.

GADOTTI, Moacir. Pedagogia da terra. 2. ed. São Paulo: Cortez, 2000. (Série Brasil Cidadão).

GIDDENS, Anthony. As consequiências da modernidade. Tradução: Raul Fiker. $6^{\text {a }}$ reimp. São Paulo: Unesp, 1991.

GIDDENS, Anthony. A vida em uma sociedade pós-tradicional. In: BECK, Ulrich;

GIDDENS, Anthony; LASH, Scott. Modernização reflexiva: política tradição e estética na ordem social moderna. São Paulo: Unesp, 2012.

JONAS, Hans. O princípio da responsabilidade: Ensaio de uma ética para a civilização tecnológica. Rio de Janeiro: Contraponto, 2006.

LEFF, Enrique. Racionalidade ambiental: a reapropriação social da natureza. Tradução de Luís Carlos Cabral. Rio de Janeiro: Civilização Brasileira, 2006.

LENZI, Cristiano Luis. Sociologia ambiental: risco e sustentabilidade na modernidade. Bauru: Edusc, 2006.

MONTERO, Carlos Eduardo Peralta. Tributação ambiental: reflexões sobre a introdução da variável ambiental no sistema tributário. São Paulo: Saraiva, 2014.

PEREIRA, Agostinho Oli Koppe; CALGARO, Cleide; GIRON, Jerônimo. Direito ambiental, sustentabilidade e pós-modernidade: Os paradigmas da reconstrução. In: PEREIRA, Agostinho Oli Koppe; CALGARO Cleide (org.). O direito ambiental e biodireito: da modernidade à pós-modernidade. Caxias do Sul: Educs, 2008.

PEREIRA, Agostinho Oli Koppe.; PEREIRA, Henrique Mioranza Koppe; PEREIRA, Mariana Mioranza Koppe. Hiperconsumo e a ética ambiental. In: PEREIRA, Agostinho Oli Koppe; HORN, Luiz Fernando Del Rio. Relações de consumo meio ambiente. Caxias do Sul: Universidade de Caxias do Sul, 2009. p. 11-27.

SACHS, Jeffrey. Economía para um planeta abarrotado. Buenos Aires: Debate, 2008. SEBASTIÃO, Simone Martins. Tributo ambiental: extrafiscalidade e função promocional do direito. Curitiba: Juruá, 2011.

SCHONARDIE, Elenise Felzke. Direito penal ambiental na sociedade do risco e imputação objetiva. Revista Ibero-Americana de Ciências Penais, Porto Alegre, ano 5, n. 56, 2004.

SOUZA. Washington Peluso Albino de. Primeiras linhas de direito econômico. 4. ed. São Paulo: LTr, 1999. 
VIEIRA, Gabriela Castro; REIS, Émilien Vilas Boas. A sociedade de risco desenfreado e os impactos ambientais. Revista Argumentum, Marília, São Paulo, v. 17, p. 139-140, 2016.

WILDNER, Márcio Leandro; OTOBELLI, Suélen: A tributação como ferramenta de controle do consumo: Reflexos sobre o meio ambiente. Revista do Curso de Direito da FGS. Caxias do Sul. Ano 5, n. 9, p. 169-191, jan/jun 2011.

WWI: The Worldwatch Institute. Estado do Mundo: Transformando Culturas - do consumismo à sustentabilidade. 2010. Diretor do Projeto: Erik Assadourian. Salvador/Bahia: UMA - Universidade Livre da Mata Atlântica, 2010. Disponível em: https://www.akatu.org.br/wp-ontent/uploads/2017/04/100629EstadodoMundo2010.pdf. Acesso: 27 abr. 2021.

WWF: WORD WIDE FUND NATURE. Consumo cada vez maior e utilização de mais recursos por população crescente aumenta a pressão sobre o planeta. Disponível em: https://www.wwf.org.br/?uNewsID=31304. Acesso: 27 mai. 2021. 